\title{
Long-term Follow-up of Pure Ductal Carcinoma in situ after Breast- Conserving Surgery
}

\author{
Keong Won Yun, M.D. ${ }^{1}$, Jisun Kim, M.D., Ph.D. ${ }^{2}$, Jong Won Lee, M.D., Ph.D. ${ }^{2}$, Sae Byul Lee, M.D., Ph.D. ${ }^{2}$, \\ Hee Jeong Kim, M.D., Ph.D. ${ }^{2}$, Il Young Chung, M.D. ${ }^{2}$, Beom Seok Ko, M.D., Ph.D. ${ }^{2}$, Byung Ho Son, M.D., Ph.D. ${ }^{2}$, \\ Sei Hyun Ahn, M.D., Ph.D. ${ }^{2}$ \\ ${ }^{1}$ Department of Surgery, Gangneung Asan Hospital, Gangneung; ${ }^{2}$ Division of Breast Surgery, Department of Surgery, University of Ulsan College of \\ Medicine, Asan Medical Center, Seoul, Korea
}

Purpose: Ductal carcinoma in situ (DCIS) is a high-risk disease for the development of invasive tumors. Although it is associated with excellent prognosis, many patients undergo extensive treatment with surgery, radiation, and endocrine therapy. This study evaluated the clinical and pathologic factors associated with invasive recurrence, particularly locoregional, distant disease after breast-conserving surgery (BCS). Methods: This study included 431 patients diagnosed with pure DCIS after BCS between January 2000 and December 2008. The clinicopathological characteristics, margin status, adjuvant therapy, and duration of endocrine therapy were evaluated in hormone receptor-positive DCIS patients. Results: The median duration of follow-up was 115 months. During this period, 37 cases (8.5\%) of recurrence were observed (12 in situ and 23 invasive recurrence and 2 unknown cases). There was no distant metastasis as first event. Similarly, none of the initial in situ recurrence cases developed distant metastasis while eight $(32 \%, 8 / 23)$ developed distant metastasis after invasive recurrence. Overall recurrence was associated with young age ( $\leq 40$ years) (HR: 3.60, 95\% confidence interval [Cl]: $1.77-7.32$ ) and hormone receptor negativity (HR: 3.33, 95\% Cl: $1.52-7.29$ ). Invasive local recurrence was independently associated with young age ( $\leq 40$ years) (HR: $3.86,95 \% \mathrm{Cl}: 1.50-$ 9.96), high nuclear grade (HR: 4.46, 95\% Cl: 1.62-12.27) and omission of adjuvant radiotherapy (HR: $6.45,95 \%$ Cl: 1.82-22.82). Notably, duration of endocrine treatment among the hormone receptor positive patient group, was numerically shorter for recurred patients, though not statistically significant. Conclusion: Young age, high nuclear grade and absence of adjuvant radiotherapy were independently associated with an increased risk of invasive recurrence. Moreover, invasive locoregional recurrence as a first event was associated with worse outcomes, yet in situ recurrence didn't affect overall survival. Further studies with larger sample sizes are warranted to confirm the prognostic indicators of recurrence and the optimal strategy for adjuvant therapy in this setting.

Key Words: Breast neoplasms, Ductal carcinoma in situ, Recurrence, Segmental mastectomy

\section{INTRODUCTION}

Ductal carcinoma in situ (DCIS) of the breast, characterized by the proliferation of presumably malignant epithelial cells within the mammary ductal system, represents a heterogeneous group of neoplasias with differing histology and biology. DCIS is frequently detected in screening mammography. Recently, the incidence of DCIS of the

Correspondence: Jisun Kim, M.D., Ph.D.

Division of Breast Surgery, Department of Surgery, University of Ulsan College of Medicine, Asan Medical Center, 88 Olympic-ro 43-gil, Songpa-gu, Seoul 05505, Korea

Tel: +82-2-3010-3935, Fax: +82-2-474-9027, E-mail: jisunkim@amc.seoul.kr This work was supported by the National Research Foundation of Korea (NRF) grant funded by the Korea government (MSIT) (No. 2015R1D1A1A01058390).

This study was supported by a grant (No 2018-767) from Asan Institute for Life Sciences, Asan Medical Center, Seoul, Korea.

Received: Feb 28, 2019 Revised: Sep 16, 2019 Accepted: Oct 5, 2019 breast has increased worldwide [1]. In Korea, the number of newly diagnosed DCIS patients has increased continuously, with an 8.7-fold increase in the incidence rate between 1999 and 2014 [2]. The National Comprehensive Cancer Network (NCCN) guidelines for the treatment of DCIS recommend excision of all disease to negative margins through mastectomy or breast-conserving surgery (BCS) with or without radiotherapy [3]. Local recurrence (LR) rates after BCS with radiotherapy are higher than those observed after mastectomy (10-15\% vs. $1-2 \%$, respectively) due to remnant ipsilateral breast tissue after BCS However, this has not translated to a difference in breast cancer-specific mortality $[4,5]$. Thus, the proportion of patients receiving BCS has increased steadily, raising concerns regarding LR. LR remains a clinical concern because the invasiveness of this recurrence is associated with mortality [6-9]. Identifying patients who are at a high risk for LR is crucial. This study aimed to identify the predictors of LR after BCS. 


\section{METHODS}

\section{Study population}

We retrospectively reviewed the records of 431 consecutive patients diagnosed with pure DCIS who underwent BCS at Asan Medical Center, Seoul, Korea between January 1, 2000 and December 31, 2008. Data were obtained from the Breast Cancer Center database of Asan Medical Center. The study protocol was approved by the Institutional Review Board of Asan Medical Center (IRB No. 2016-0229). Patients with a history of invasive cancer treated previously or with simultaneous contralateral invasive tumors were excluded. Demographic, pathologic, treatment, and follow-up variables were analyzed including- tumor size, nuclear grade, comedo necrosis, multifocality, hormone receptor and human epidermal growth factor receptor 2 (HER2) status (positive or negative) by immunohistochemical (IHC) staining, and microscopic resection margin. Further fluorescence in situ hybridization for HER2 scores of $2+$ by IHC staining was not done. Surgical margin was defined as "negative" if there was no ink on the tumor. Nuclear grades were analyzed using a dichotomous scale (low and high).

The follow-up evaluations included a physical examination and mammography with/without ultrasound every 6 months. Ultrasonography-guided core needle biopsy or fine-needle aspiration was performed for pathological confirmation for suspicious lesions. An ipsilateral breast tumor recurrence (IBTR) was defined as a recurrent in situ or invasive carcinoma occurring after BCS in either the skin or parenchyma of the ipsilateral breast. Regional failure was defined as recurrence in the regional lymph nodes including the ipsilateral axillary nodes, and supraclavicular neck nodes without any evidence of IBTR.

\section{Statistical analysis}

All statistical analyses were performed using IBM SPSS Statistics for Windows, version 22.0 (IBM Corp., Armonk, USA). The non-recurrence and recurrence groups were compared using Chi-square or Fisher's exact tests for categorical data and Student's t or Mann-Whitney U tests for continuous data with non-normal distributions. The rates of recurrence-free survival were estimated using the Kaplan-Meier method and the significance of the differences was determined using logrank tests. Variables identified as likely to be associated with disease-free survival $(p<0.2)$ via univariate analysis were included in a multivariate Cox proportional hazards regression model. The multivariate analysis attempted to identify the predictors of LR in patients with DCIS. The adjusted hazard ratios (HRs), and 95\% confidence intervals (CIs) were calculated. P-values $<0.05$ denoted statistical significance.

\section{RESULTS}

\section{Clinicopathological characteristics}

Total of 431 patients diagnosed with pure DCIS were treated with BCS. The median duration of follow-up after surgery was 115 months (range: 3-195 months). Median age at diagnosis was 47 years (range: 19-82 years). Following BCS, adjuvant radiotherapy was performed in 401 patients (93\%). Permanent involvement of the resection margins was noted in 38 cases ( $8.8 \%$ ) and all underwent subsequent radiotherapy. Overall recurrence were reported among 37 patients (8.6\%) with 5-year and 10-year total recurrence rates of $4 \%$ and $6.5 \%$, respectively. Among the 37 patients with recurrence, five had regional lymph node metastasis and two had concurrent IBTR. While distant metastasis was not observed as the first event, 8 patients had distant metastasis after locoregional event. Fifteen patients developed subsequent contralateral breast tumors. Characteristics of the study population are summarized in Table 1.

\section{Factors associated with Loco-regional recurrence (LR)}

Of the 37 patients who developed recurrence during the follow-up period, 12 (32.4\%) and 23 (62.2\%) developed non-invasive and invasive recurrence respectively with 2 unknown cases. In univariate analysis, age, hormone receptor status and IHC-defined subtype were associated with overall recurrence while presence of comdo necrosis, positive resection margin, nor adjuvant radiotherapy were not (Table 2). Younger age ( $\leq 40$ years) (HR: $3.60,95 \% \mathrm{CI}: 1.77-7.32)$ and hormone receptor negativity (HR: 3.33, 95\% CI: 1.52-7.29) were independently associated with overall recurrence in multivariate analysis (Table 3). When excluding in situ recurrence, younger age, higher nuclear grade, IHC-defined subtype and omitting radiotherapy were associated with invasive recurrence in univariate analysis (Table 2). The Cox proportional hazards model showed age $\leq 40$ years (HR: 3.86, 95\% CI: 1.50-9.96), high nuclear grade (HR: 4.46, 95\% CI: 1.62-12.27), and absence of radiotherapy (HR: 6.45, 95\% CI: 1.82-22.82) to be in- 
Table 1. Clinicopathological characteristics of patients

\begin{tabular}{|c|c|}
\hline Variable & $\begin{array}{l}n=431 \\
\text { No. }(\%)\end{array}$ \\
\hline Median age at diagnosis, years (range) & $47(19-82)$ \\
\hline Simultaneous bilateral DCIS & $7(1.6)$ \\
\hline \multicolumn{2}{|l|}{ Resection margin } \\
\hline Negative & $393(91.2)$ \\
\hline Positive & $38(8.8)$ \\
\hline \multicolumn{2}{|l|}{ Nuclear grade } \\
\hline 1 & $81(18.8)$ \\
\hline 2 & $263(61.0)$ \\
\hline 3 & $55(12.8)$ \\
\hline Unknown & $32(7.4)$ \\
\hline \multicolumn{2}{|l|}{ Comedo necrosis } \\
\hline Yes & $181(42.0)$ \\
\hline No & $162(37.6)$ \\
\hline Unknown & $88(20.4)$ \\
\hline \multicolumn{2}{|l|}{ ER } \\
\hline Positive & $323(74.9)$ \\
\hline Negative & $64(14.8)$ \\
\hline Unknown & $44(10.3)$ \\
\hline \multicolumn{2}{|l|}{ PR } \\
\hline Positive & $300(69.6)$ \\
\hline Negative & $87(20.2)$ \\
\hline Unknown & $44(10.2)$ \\
\hline \multicolumn{2}{|l|}{ HER2 } \\
\hline Positive & $83(19.3)$ \\
\hline Negative & $235(54.5)$ \\
\hline Unknown & $113(26.2)$ \\
\hline \multicolumn{2}{|l|}{ IHC-defined subtype } \\
\hline HR positive/HER2 negative & $224(52.0)$ \\
\hline HR positive/HER2 positive & $53(12.3)$ \\
\hline HR negative/HER2 positive & $30(7.0)$ \\
\hline Triple negative & $11(2.6)$ \\
\hline Unknown & $113(26.1)$ \\
\hline \multicolumn{2}{|l|}{ Radiotherapy } \\
\hline Yes & $401(93.0)$ \\
\hline No & $24(5.6)$ \\
\hline Unknown & $6(1.4)$ \\
\hline \multicolumn{2}{|l|}{ Endocrine therapy } \\
\hline Yes & $300(69.6)$ \\
\hline No & $120(27.8)$ \\
\hline Unknown & $11(2.6)$ \\
\hline \multicolumn{2}{|l|}{ Event during follow-up } \\
\hline Recurrence & $37(8.6)$ \\
\hline IBTR only & 30 \\
\hline Non-invasive & 12 \\
\hline Invasive & 18 \\
\hline IBTR+regional failure & 3 \\
\hline Regional failure only & 2 \\
\hline Unknown & 2 \\
\hline Contralateral breast tumor & $15(3.5)$ \\
\hline Non-invasive & 7 \\
\hline Invasive & 8 \\
\hline
\end{tabular}

$\mathrm{DCIS}=$ ductal carcinoma in situ; $\mathrm{ER}=$ estrogen receptor; $\mathrm{PR}=$ progesterone receptor; HER2 = human epidermal growth factor receptor 2 ; IHC=immunohistochemistry; IBTR = in-breast tumor recurrence.
Table 2. Comparison of clinicopathologic characteristics by recurrence status

\begin{tabular}{|c|c|c|c|c|c|}
\hline Characteristic & $\begin{array}{c}\text { NED } \\
n=394 \\
\text { No. (\%) }\end{array}$ & $\begin{array}{c}\text { Overall } \\
\text { recurrence } \\
n=37 \\
\text { No. }(\%)\end{array}$ & $p$-value & $\begin{array}{c}\text { Invasive } \\
\text { LR } \\
n=21 \\
\text { No. (\%) }\end{array}$ & $p$-value \\
\hline Age at diagnosis & & & 0.004 & & 0.012 \\
\hline$\leq 40$ & $84(21.3)$ & $16(43.2)$ & & $10(47.6)$ & \\
\hline$>40$ & $310(78.7)$ & $21(56.8)$ & & $11(52.4)$ & \\
\hline HR status & & & 0.010 & & 0.059 \\
\hline Positive & $316(80.2)$ & $23(62.2)$ & & $14(66.7)$ & \\
\hline Negative & $39(9.9)$ & $9(24.3)$ & & $5(23.8)$ & \\
\hline Unknown & $39(9.9)$ & $5(13.5)$ & & $2(9.5)$ & \\
\hline HER2 status & & & 0.129 & & 0.697 \\
\hline Positive & $74(18.8)$ & $9(24.3)$ & & $3(14.3)$ & \\
\hline Negative & $222(56.3)$ & $13(35.1)$ & & $6(28.6)$ & \\
\hline Unknown & $98(24.9)$ & $15(40.5)$ & & $12(57.1)$ & \\
\hline IHC-defined subtype & & & 0.008 & & 0.024 \\
\hline HRpositive/HER2negative & $212(53.8)$ & $12(32.4)$ & & $5(23.8)$ & \\
\hline HRpositive/HER2positive & $51(12.9)$ & $2(5.4)$ & & 0 & \\
\hline HRnegative/HER2positive & $23(5.8)$ & $7(18.9)$ & & $3(14.3)$ & \\
\hline Triple negative & $10(2.5)$ & $1(2.7)$ & & $1(4.8)$ & \\
\hline Unknown & $98(24.9)$ & $15(40.5)$ & & $12(57.1)$ & \\
\hline Radiation therapy & & & 0.135 & & 0.028 \\
\hline Yes & $369(93.6)$ & $32(86.5)$ & & $17(81.0)$ & \\
\hline No & $20(5.1)$ & $4(10.8)$ & & $4(19.0)$ & \\
\hline Unknown & $5(1.3)$ & $1(2.7)$ & & 0 & \\
\hline Resection margin & & & 0.760 & & 1.0 \\
\hline Free & $358(90.9)$ & $35(94.6)$ & & $19(90.5)$ & \\
\hline Involvement & $36(9.1)$ & $2(5.4)$ & & $2(9.5)$ & \\
\hline Parenchymal pattern & & & 0.709 & & 1.0 \\
\hline $1 / 2$ & $188(47.7)$ & $18(48.6)$ & & $10(47.6)$ & \\
\hline $3 / 4$ & $163(41.4)$ & $13(35.1)$ & & $8(38.1)$ & \\
\hline Unknown & $43(10.9)$ & $6(16.2)$ & & $3(14.3)$ & \\
\hline Nuclear grade & & & 0.121 & & 0.043 \\
\hline Low & $317(80.5)$ & $27(73.0)$ & & $14(66.6)$ & \\
\hline High & $47(11.9)$ & $8(21.6)$ & & $6(28.6)$ & \\
\hline Unknown & $30(7.6)$ & $2(5.4)$ & & $1(4.8)$ & \\
\hline Necrosis & & & 0.239 & & 0.604 \\
\hline Absence & $152(38.6)$ & $10(27.0)$ & & $6(28.6)$ & \\
\hline Presence & $163(41.4)$ & $18(48.6)$ & & $9(42.8)$ & \\
\hline Unknown & $79(20.0)$ & $9(24.3)$ & & $6(28.6)$ & \\
\hline Microcalcification & & & 0.054 & & 0.36 \\
\hline Absence & $144(36.5)$ & $21(56.8)$ & & $10(47.6)$ & \\
\hline Presence & $204(51.8)$ & $15(40.5)$ & & $11(52.4)$ & \\
\hline Unknown & $46(11.7)$ & $1(2.7)$ & & 0 & \\
\hline Multifocality & & & 0.638 & & 0.356 \\
\hline No & $329(83.5)$ & $30(81.1)$ & & $16(76.2)$ & \\
\hline Yes & $61(15.5)$ & $7(18.9)$ & & $5(23.8)$ & \\
\hline Unknown & $4(1.0)$ & 0 & & 0 & \\
\hline Tumor size (cm) & & & 0.306 & & 0.626 \\
\hline Mean & $1.24 \pm 1.15$ & $1.44 \pm 1.08$ & & $1.36 \pm 1.02$ & \\
\hline Range & $0.10-9.00$ & $0.30-4.80$ & & $0.40-4.80$ & \\
\hline
\end{tabular}

$\mathrm{NED}=$ no evidence of disease; $\mathrm{LR}=$ local recurrence; $\mathrm{HR}=$ hormone recptor; $\mathrm{HER} 2$ = human epidermal growth factor receptor 2; $\mathrm{IHC}=$ immunohistochemistry. 
dependently associated with greater risk of invasive recurrence (Table 3). The Kaplan-Meier curves demonstrating the magnitude of these variables on the rates of 10-year recurrence-free survival are shown in
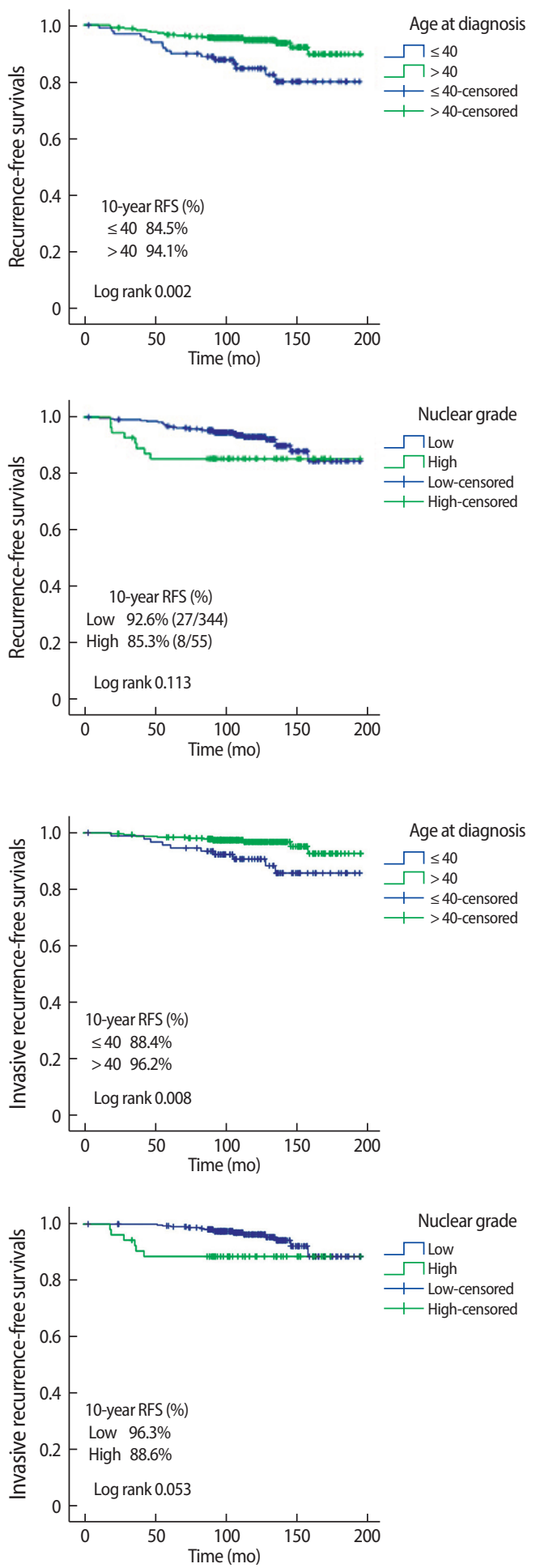

Figure 1.

After excluding 113 patients with unknown HER2 status, the remaining 318 patients were classified according to the following four
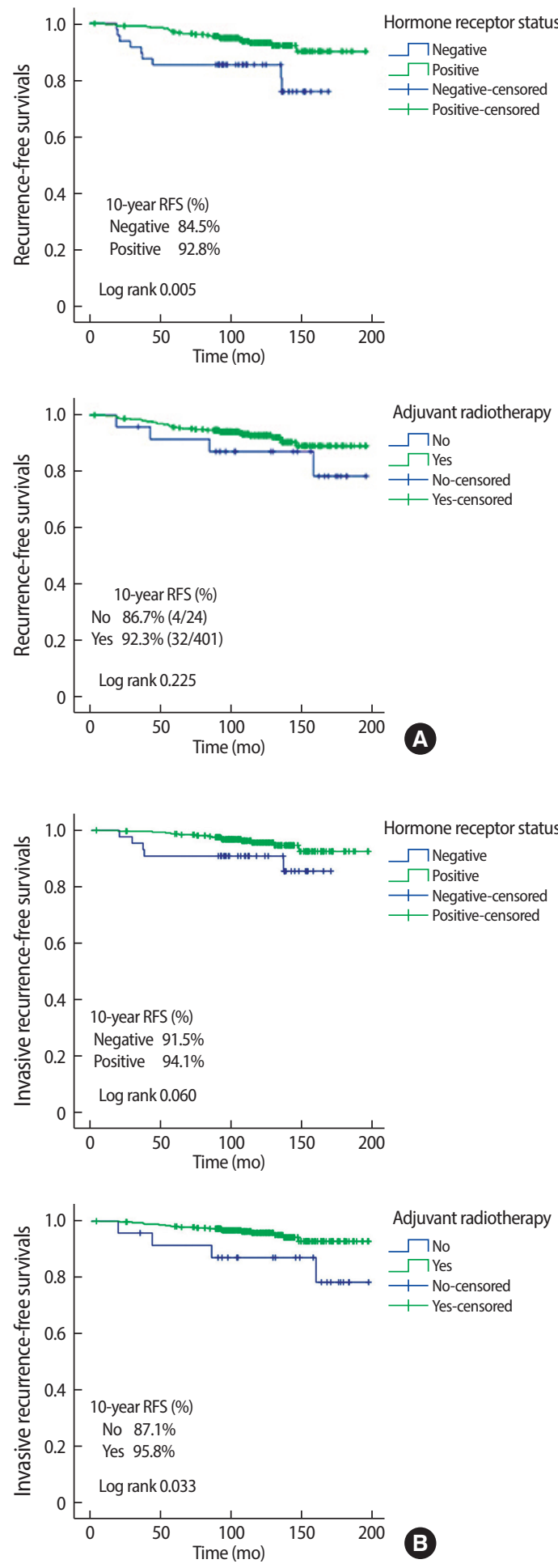

Figure 1. Kaplan-Meier plots showing the effects of variables on (A) recurrence-free survival, (B) invasive recurrence-free survival. 
Table 3. Multivariate analysis of predictive risk factors of local recurrence by Cox proportional hazard model

\begin{tabular}{|c|c|c|c|}
\hline \multirow[b]{2}{*}{ Variable } & \multicolumn{2}{|c|}{ Overall recurrence } & \multirow[b]{2}{*}{$p$-value } \\
\hline & Hazard ratio & $\begin{array}{c}95 \% \\
\text { Confidence interval }\end{array}$ & \\
\hline \multicolumn{4}{|l|}{ Age at diagnosis } \\
\hline$\leq 40$ years $($ vs. $>40)$ & 3.60 & $1.77-7.32$ & $<0.001$ \\
\hline \multicolumn{4}{|l|}{ HR status } \\
\hline Negative (vs. Positive) & 3.33 & $1.52-7.29$ & 0.003 \\
\hline \multicolumn{4}{|l|}{ Adjuvant RT } \\
\hline No (vs. Yes) & 1.78 & $0.23-13.49$ & 0.579 \\
\hline \multirow[b]{2}{*}{ Variable } & \multicolumn{2}{|c|}{ Invasive LR } & \multirow[b]{2}{*}{$p$-value } \\
\hline & Hazard ratio & $\begin{array}{l}95 \% \\
\text { Confidence interval }\end{array}$ & \\
\hline \multicolumn{4}{|l|}{ Age at diagnosis } \\
\hline$\leq 40$ years $($ vs. $>40)$ & 3.86 & $1.50-9.96$ & 0.005 \\
\hline \multicolumn{4}{|l|}{ Nuclear grade } \\
\hline High (vs. Low) & 4.46 & $1.62-12.27$ & 0.004 \\
\hline \multicolumn{4}{|l|}{ Adjuvant RT } \\
\hline No (vs. Yes) & 6.45 & $1.82-22.82$ & 0.004 \\
\hline
\end{tabular}

$\mathrm{HR}=$ hormone receptor; $\mathrm{RT}=$ radiotherapy; $\mathrm{LR}=$ local recurrence.

phenotypes: HRpositive/HER2negative, HRpositive/HER2positive, HRnegative/HER2positive and triple negative subtypes. IHC-defined subtype was associated with both overall and invasive local recurrence in univariate analysis (Table $2, p=0.008, p=0.024$ ). However, the subtype was not significantly associated with neither overall and invasive recurrence in multivariate analysis.

Subgroup analysis performed in patients with positive hormone receptor status showed that $79.4 \%$ (269/339) received endocrine therapy, and $71.4 \%(192 / 269)$ completed endocrine therapy for 5 years while $28.6 \%$ discontinued. Recurrence in the ipsilateral breast or regional lymph nodes was observed in 23 patients, while contralateral breast cancers were observed in 14 patients among the 339 hormone receptor positive patients. The mean duration of endocrine therapy was shorter in patients with a breast event versus that in patients without $(31.3 \pm 27.6$ vs. $41.1 \pm 25.4$ months, respectively); however, this difference was not statistically significant $(p=0.075)$.

All locoregional recurrence cases undergone surgical excision. Among 23 invasive recurrence cases, 10 patients have undergone breast conservation, 11 with salvage mastectomy and 2 with axillary lymph node excision. Subsequent systemic therapy was performed according to the invasive tumor size, hormone receptor and HER2 status.

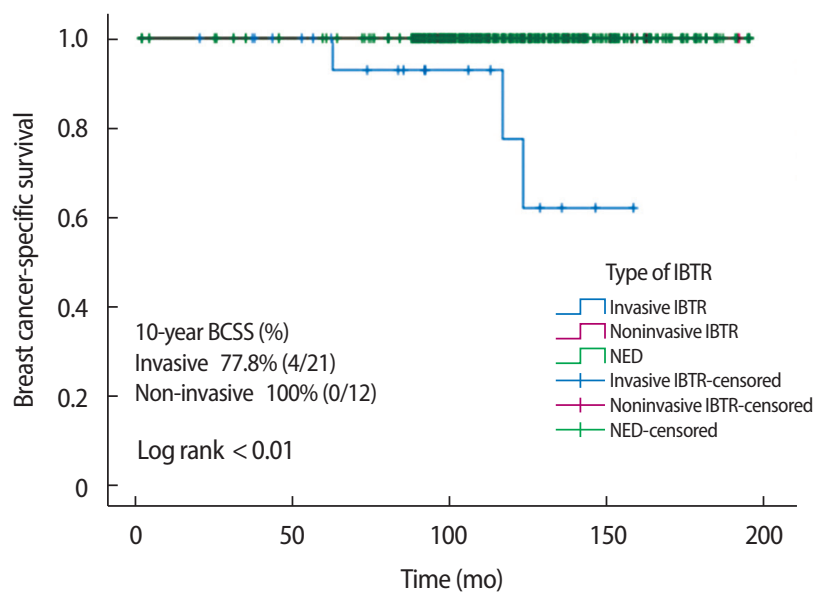

Figure 2. Kaplan-Meier estimates breast cancer-specific survival according to the type of recurrence.

Distant metastasis and survival after the first recurrence

Metastatic disease or death caused by breast cancer did not occur in any of the 12 patients with non-invasive recurrences. Among the remaining patients, eight $(32 \%, 8 / 25)$ developed distant metastasis after first recurrence. Four patients developed bone metastases, 2 patients developed lung metastasis and 1 patient with liver metastasis with distant lymph nodes (one patient with unknown site). The median time from the first recurrence to distant metastasis was 30 (range: 25-61) months. At the last follow-up, seven patients had died due to the disease. The median time from the date of diagnosis of distant metastasis until death was 32 (range: 12-67) months. Breast cancer-specific survival between invasive vs in situ recurrence is displayed in Figure 2.

\section{DISCUSSION}

Previously reported rates of LR ranged between 9\% and 21\%, with half of the recurrence cases identified as invasive $[5,10,11]$. In the present study, LR developed as the first event in 37 patients and was invasive in 23 of those (65.7\%, 23/35, 2 invasiveness unknown). These lower rates and relatively higher proportion of invasiveness compared to those in other studies are linked to the treatment protocols implemented in Asan Medical Center. Most patients (93\%) treated with BCS received radiotherapy. During follow-up, screening via mammography and physical examination were performed biannually on conservatively treated patients in Asan Medical Center. Silverstein et al. [12] reported that the diagnosis of recurrent tumors is more chal- 
lenging after radiotherapy due to radiotherapy-related fibrosis and scarring which obscure the signs of LR. Moreover, breast density lowers the sensitivity of mammography and studies have shown higher breast density in Korean versus Western women [13]. For patients with dense breasts, the selective use of sonography may be helpful.

In the present study, younger age at diagnosis ( $\leq 40$ years) was a predictive factor for all types of LR. Invasive breast cancer in younger patients is generally associated with poor biological factors and treatment outcomes. However, such data are currently limited for patients with DCIS. A study investigating the long-term outcomes after BCS followed by definitive breast irradiation in women with asymptomatic DCIS of the breast showed that patients aged $\geq 50$ years at the time of treatment initiation had with lower rates of LR [11]. Although the definition of "young age" is not absolute, relatively younger patients tend to be associated with diseases with more aggressive pathology. Vicini and Recht[14] reported a higher incidence nuclear grade 3 DCIS in patients aged $<45$ years compared to that in older patients $(p=0.003)$, while necrosis was more common in tumors found in younger patients ( $p=0.01)$. In addition, Schouten et al. [15] reported that younger patients $(<50$ years) with DCIS were treated with mastectomy less frequently compared to older patients $(p<0.01)$. In the present study, younger patients were linked to negative-hormone receptor status. The mean duration of hormone therapy was shorter in patients aged $\leq 40$ years. However, after adjusting for other factors, only age remained significant.

Despite the heterogeneity of DCIS, it may be categorized according to nuclear grade. Numerous studies have shown the association between a high nuclear grade and LR. A population-based study showed that the 10-year actuarial rate of LR was higher in patients with high nuclear grade than that in patients with low or intermediate nuclear grade disease [16]. In addition, the association between nuclear grade and risk of LR was demonstrated in a meta-analysis of 16 trials involving a total of 10,526 women with DCIS [17]. The results showed an increased risk in patients with a higher nuclear grade of DCIS. Low nuclear grades (grades 1-2) and an absence of necrosis were associated with a reduced risk of ipsilateral breast events [18]. The present study showed that high-grade tumors were more likely to recur with an invasive nature compared to intermediate- or low-grade tumors.

Various studies have reported that radiotherapy reduced the incidence of invasive and non-invasive recurrence. The European Orga- nization for Research and Treatment of Cancer (EORTC) trial reported that the use of radiotherapy after excision of DCIS led to a $47 \%$ reduction of LR 10 years after treatment. This effect was maintained long-term, with a $48 \%$ reduction reported 15 years after treatment [5,7]. In the National Surgical Adjuvant Breast and Bowel Project (NSABP) B-17 trial, a randomized clinical trial with a median follow-up of 17.3 years, radiotherapy reduced the risk of LR by approximately $50 \%$ [10]. In another trial with a median follow-up of 12.7 years, the reduction of risk derived from radiotherapy ranged from 30\% to 56\% [19]. A meta-analysis of randomized trials (including the aforementioned trials) reported a reduced risk of LR after radiotherapy irrespective of the age at diagnosis, tumor size, grade, and margin status [20]. In the present analysis, radiotherapy was associated only with the risk of invasive LR.

The IHC-defined subtype was unavailable in approximately one-quarter of patients included in this study. The low incidence of events did not permit multivariate analysis focusing on invasive IBTR. The rate of recurrence was higher in the HRnegative/HER2positive group despite its small proportion in the study population. Currently, there is limited and conflicting evidence concerning the prognostic significance of molecular phenotypes in DCIS. Williams et al. [21] suggested an association between luminal B, HER-2, and triple-negative DCIS and recurrence compared to that for luminal A DCIS. Other reports confined to invasive breast cancer showed similar results [22]. In contrast, no significant correlation was found between various biological markers and disease recurrence $[23,24]$. In future studies, determining the molecular phenotype through IHC analysis may be useful in identifying predictive factors.

Based on the NCCN guidelines, patients with a positive hormone receptor status are treated with endocrine therapy. The NSABP B-24 trial showed that the benefits of tamoxifen may be confined to hormone receptor-positive DCIS [25]. Tamoxifen administered as adjuvant therapy after BCS is beneficial in reducing ipsilateral recurrence and contralateral events in ER-positive DCIS patients [19,25]. In the current study, 79.1\% of hormone receptor-positive patients received low-dose tamoxifen. However, the results did not show significant effects on ipsilateral recurrence and contralateral events. An additional analysis of adherence to tamoxifen may help explain this discrepancy.

Other risk factors reported in the literature (close or positive margins, comedonecrosis, and/or large tumor size) [11,24,26,27], were not 
statistically significant in the present study.

This study demonstrated that the incidence of distant metastasis after an initial diagnosis of pure DCIS is rare. In the NSABP B-17 trial, only 6 of the 814 enrolled patients developed metastasis as a first event after treatment with partial mastectomy with or without radiotherapy [28]. Bannani et al. [29] reported distant metastasis in 4 of 218 patients treated with mastectomy for DCIS. The low incidence of distant metastasis restricted further statistical analysis. Interestingly, all patients who developed metastasis after a diagnosis of pure DCIS have intervening invasive locoregional recurrence. In the EORTC 10853 trial, a diagnosis of invasive LR increased the risk of mortality by five-fold compared to that in patients without LR [7]. Romero et al. [6] assessed patient survival in a subgroup of 53 DCIS patients with invasive recurrence. The 10 -year breast cancer-specific survival rate was $85 \%$, similar to that of patients with stage IIA disease. Therefore, invasive LR should be prevented. Buist et al. [30] also showed that patients with initial DCIS are associated with substantially higher incidence rates of secondary cancer regardless of initial treatment. Although the 5-year survival rate of DCIS is almost $100 \%$, adherence to surveillance in patients after BCS is crucial for the early detection of invasive LR and secondary cancer.

The present study has several limitations. This was a retrospective study conducted in a single center without centralized pathologic review. The limited number of events in the total DCIS population limited the statistical power of the analysis and subgroup analyses couldn't be done owing to small numbers.

In conclusion, invasive recurrence after pure DCIS was associated with age at diagnosis, nuclear grade, and adjuvant radiotherapy. Individual evaluation of these prognostic factors may help identify patients requiring active treatment and close monitoring.

\section{CONFLICT OF INTEREST}

The authors declare that they have no competing interests.

\section{REFERENCES}

1. Virnig BA, Tuttle TM, Shamliyan T, Kane RL. Ductal carcinoma in situ of the breast: a systematic review of incidence, treatment, and outcomes. J Natl Cancer Inst 2010;102:170-8.
2. Park EH, Min SY, Kim Z, Yoon CS, Jung KW, Nam SJ, et al. Basic facts of breast cancer in Korea in 2014: the 10-year overall survival progress. J Breast Cancer 2017;20:1-11.

3. Carlson RW, Allred DC, Anderson BO, Burstein HJ, Carter WB, Edge SB, et al. Breast cancer. Clinical practice guidelines in oncology. J Natl Compr Canc Netw 2009;7:122-92.

4. Houghton J, George WD, Cuzick J, Duggan C, Fentiman IS, Spittle $\mathrm{M}$, et al. Radiotherapy and tamoxifen in women with completely excised ductal carcinoma in situ of the breast in the UK, Australia, and New Zealand: randomised controlled trial. Lancet 2003;362: 95-102.

5. Group EBCC, Group ER, Bijker N, Meijnen P, Peterse JL, Bogaerts J, et al. Breast-conserving treatment with or without radiotherapy in ductal carcinoma-in-situ: ten-year results of European Organisation for Research and Treatment of Cancer randomized phase III trial 10853--a study by the EORTC Breast Cancer Cooperative Group and EORTC Radiotherapy Group. J Clin Oncol 2006;24:3381-7.

6. Romero L, Klein L, Ye W, Holmes D, Soni R, Silberman H, et al. Outcome after invasive recurrence in patients with ductal carcinoma in situ of the breast. Am J Surg 2004;188:371-6.

7. Donker M, Litiere S, Werutsky G, Julien JP, Fentiman IS, Agresti R, et al. Breast-conserving treatment with or without radiotherapy in ductal carcinoma in situ: 15-year recurrence rates and outcome after a recurrence, from the EORTC 10853 randomized phase III trial. J Clin Oncol 2013;31:4054-9.

8. Roses RE, Arun BK, Lari SA, Mittendorf EA, Lucci A, Hunt KK, et al. Ductal carcinoma-in-situ of the breast with subsequent distant metastasis and death. Ann Surg Oncol 201 1;18:2873-8.

9. Narod SA, Iqbal J, Giannakeas V, Sopik V, Sun P. Breast Cancer Mortality After a Diagnosis of Ductal Carcinoma In Situ. JAMA Oncol 2015;1:888-96.

10. Wapnir IL, Dignam JJ, Fisher B, Mamounas EP, Anderson SJ, Julian $\mathrm{TB}$, et al. Long-term outcomes of invasive ipsilateral breast tumor recurrences after lumpectomy in NSABP B-17 and B-24 randomized clinical trials for DCIS. J Natl Cancer Inst 201 1;103:478-88.

11. Solin LJ, Fourquet A, Vicini FA, Taylor M, Olivotto IA, Haffty B, et al. Long-term outcome after breast-conservation treatment with radiation for mammographically detected ductal carcinoma in situ of the breast. Cancer 2005;103:1137-46.

12. Silverstein MJ, Lagios MD, Martino S, Lewinsky BS, Craig PH, 
Beron PJ, et al. Outcome after invasive local recurrence in patients with ductal carcinoma in situ of the breast. J Clin Oncol 1998;16: 1367-73.

13. Youn I, Choi S, Kook SH, Choi YJ. Mammographic breast density fvaluation in Korean women using fully automated volumetric assessment. J Korean Med Sci 2016;31:457-62.

14. Vicini FA, Recht A. Age at diagnosis and outcome for women with ductal carcinoma-in-situ of the breast: a critical review of the literature. J Clin Oncol 2002;20:2736-44.

15. Schouten van der Velden AP, Peeters PH, Koot VC, Hennipman A. Local recurrences after conservative treatment of ductal carcinoma-in-situ of the breast without radiotherapy: the effect of age. Ann Surg Oncol 2006;13:990-8.

16. Rakovitch E, Nofech-Mozes S, Narod SA, Hanna W, Thiruchelvam D, Saskin R, et al. Can we select individuals with low risk ductal carcinoma in situ (DCIS)? A population-based outcomes analysis. Breast Cancer Res Treat 2013;138:581-90.

17. Wang SY, Shamliyan T, Virnig BA, Kane R. Tumor characteristics as predictors of local recurrence after treatment of ductal carcinoma in situ: a meta-analysis. Breast Cancer Res Treat 2011;127:1-14.

18. Ringberg A, Nordgren H, Thorstensson S, Idvall I, Garmo H, Granstrand B, et al. Histopathological risk factors for ipsilateral breast events after breast conserving treatment for ductal carcinoma in situ of the breast--results from the Swedish randomised trial. Eur J Cancer 2007;43:291-8.

19. Cuzick J, Sestak I, Pinder SE, Ellis IO, Forsyth S, Bundred NJ, et al. Effect of tamoxifen and radiotherapy in women with locally excised ductal carcinoma in situ: long-term results from the UK/ANZ DCIS trial. Lancet Oncol 2011;12:21-9.

20. Early Breast Cancer Trialists' Collaborative G, Correa C, McGale P, Taylor C, Wang Y, Clarke M, et al. Overview of the randomized trials of radiotherapy in ductal carcinoma in situ of the breast. J Natl Cancer Inst Monogr 2010;2010:162-77.

21. Williams KE, Barnes NL, Cramer A, Johnson R, Cheema K, Morris J, et al. Molecular phenotypes of DCIS predict overall and invasive recurrence. Ann Oncol 2015;26:1019-25.
22. Dawood S, Hu R, Homes MD, Collins LC, Schnitt SJ, Connolly J, et al. Defining breast cancer prognosis based on molecular phenotypes: results from a large cohort study. Breast Cancer Res Treat 2011;126:185-92.

23. Cornfield DB, Palazzo JP, Schwartz GF, Goonewardene SA, Kovatich AJ, Chervoneva I, et al. The prognostic significance of multiple morphologic features and biologic markers in ductal carcinoma in situ of the breast: a study of a large cohort of patients treated with surgery alone. Cancer 2004;100:2317-27.

24. Kim JY, Park K, Kang G, Kim HJ, Gwak G, Shin YJ. Predictors of Recurrent Ductal Carcinoma In Situ after Breast-Conserving Surgery. J Breast Cancer 2016;19:185-90.

25. Allred DC, Anderson SJ, Paik S, Wickerham DL, Nagtegaal ID, Swain SM, et al. Adjuvant tamoxifen reduces subsequent breast cancer in women with estrogen receptor-positive ductal carcinoma in situ: a study based on NSABP protocol B-24. J Clin Oncol 2012; 30:1268-73.

26. Mele A, Mehta P, Slanetz PJ, Brook A, Recht A, Sharma R. Breast-conserving surgery alone for ductal carcinoma in situ: factors associated with increased risk of local recurrence. Ann Surg Oncol 2017;24:1221-6.

27. Mathew J, Karia R, Morgan DAL, Lee AHS, Ellis IO, Robertson JFR, et al. Factors influencing local control in patients undergoing breast conservation surgery for ductal carcinoma in situ. Breast 2017;31:181-5

28. Fisher B, Dignam J, Wolmark N, Mamounas E, Costantino J, Poller $\mathrm{W}$, et al. Lumpectomy and radiation therapy for the treatment of intraductal breast cancer: findings from National Surgical Adjuvant Breast and Bowel Project B-17. J Clin Oncol 1998;16:441-52.

29. Bannani S, Rouquette S, Bendavid-Athias C, Tas P, Leveque J. The locoregional recurrence post-mastectomy for ductal carcinoma in situ: Incidence and risk factors. Breast 2015;24:608-12.

30. Buist DS, Abraham LA, Barlow WE, Krishnaraj A, Holdridge RC, Sickles EA, et al. Diagnosis of second breast cancer events after initial diagnosis of early stage breast cancer. Breast Cancer Res Treat 2010;124:863-73. 